\title{
FACTORS RESPONSIBLE FOR POOR VISUAL OUTCOME IN FUNGAL
}

\section{KERATITIS}

Pankaj Choudhary' ${ }^{1}$, Sujatha Lakhtakia², Charudatt Chalisgoankar³, Anamika Dwivedi' ${ }^{4}$, Kanchanbala Rathore ${ }^{5}$

\section{HOW TO CITE THIS ARTICLE:}

Pankaj Choudhary, Sujatha Lakhtakia, Charudatt Chalisgoankar, Anamika Dwivedi, Kanchanbala Rathore. "Factors Responsible for Poor Visual Outcome in Fungal Keratitis". Journal of Evolution of Medical and Dental Sciences 2015; Vol. 4, Issue 57, July 16; Page: 9938-9945, DOI:10.14260/jemds/2015/1438

ABSTRACT: Infectious keratitis is a potentially sight threatening ocular condition and about, $44 \%$ of all central corneal ulcers are caused by fungi. Fungal keratitis is more common in warmer climates and rural areas and often follows trauma to the cornea especially by organic vegetative matter or objects contaminated by soil. Application of topical steroid drops, TEM use and other predisposing factors often leads to an exacerbation of infection, affecting final visual acuity. These factors coupled with delay in presentation as symptoms are less compared to signs, further affects the visual outcome. The present study evaluated the incidence of fungal keratitis in relation to age, sex, occupation and season in a hospital based population and also to identify risk affecting the visual outcome. Incidence of fungal keratitis cases was maximum in 41-60 years, and more common in males, illiterate persons, and those belonging to low socio economic status. It was more common in farmers and the factors affecting the final visual outcome included patients aged more than 40 years $(\mathrm{p}<0.05)$ and those presenting after 7 days $(\mathrm{p}<0.05)$, with history of topical steroid $(\mathrm{p}<0.05)$ use had a significantly poorer visual outcome. Similarly patients with central ulcers $(\mathrm{p}<0.05)$, especially those associated with hypopyon $(\mathrm{p}<0.05 \%)$ also had a significantly less favourable visual outcome. However, use of TEM and type of fungal infection were not significantly related to poor outcome in terms of visual acuity.

KEYWORDS: Fungal keratitis, Risk factors, Visual outcome.

INTRODUCTION: Keratitis is an inflammation of the cornea produced by infectious organisms or non-infectious agents and is a leading cause of monocular blindness in developing countries like India.[1],[2] Infectious keratitis can be caused by bacteria, viruses, fungi and parasites. It is a potentially sight threatening ocular condition and about, 44\% of all central corneal ulcers are caused by fungi..[3]

Fungal keratitis is more common in warmer climates and rural areas. It often follows trauma to the cornea, especially by organic vegetative matter or object contaminated by soil. Majority of the patients (65.4\%) are usually associated with agricultural work. ${ }^{[3]}$ Topical application of corticosteroids also predisposes to fungal keratitis. ${ }^{[4]}$ Other disorders, including corneal surface disorders, dry eye, bullous keratopathy, and exposure keratitis are associated with development of ulcerative keratitis.[5] In India, 47\% of patients were found to have used traditional eye medicines before presentation to hospital.[6]

Visual outcomes after fungal keratitis are often unsatisfactory. The present study aims to evaluate the incidence of fungal keratitis in relation to age, sex, occupation and season in hospital based population and also to identify risk affecting the visual outcome.

MATERIAL AND METHODS: This was a hospital based observational study conducted in the Department of Ophthalmology, S. S. Medical College, Rewa (M. P.), from July 2011 to June 2013. One hundred twenty seven consecutive patients of fungal keratitis were enrolled for the study after applying the following criteria. 


\section{ORIGINAL ARTICLE}

\section{Inclusion Criteria:}

1. Clinically diagnosed fungal keratitis cases with characteristic features and confirmed by $10 \%$ KOH mount.

2. Cases of fungal keratitis diagnosed and treated elsewhere.

\section{Exclusion Criteria:}

1. Bacterial and viral keratitis.

2. Any other corneal pathology causing visual impairment.

At the time of presentation, a case record was prepared to document the patient particulars. Details regarding onset of disease, complaints, history of trauma, use of topical steroids and traditional eye medicines (TEM) were recorded. Medical history i.e. history of diabetes or any other cause of systemic immunosuppression was recorded. Past history of ocular surgery, any other ocular disease and treatment were noted.

All patients underwent a comprehensive ophthalmic examination that included, best corrected visual acuity, anterior segment examination by slit lamp and posterior segment examination where possible, by direct and indirect ophthalmoscope. Special attention was given to the examination of cornea. Fluorescein staining of ulcer was done and was then examined in cobalt blue filter under following headings - site, size, margins, floor, and depth, surrounding area around ulcer, density of infiltration, vascularisation, and degree of stromal edema. Corneal sensation was tested and presence of satellite lesions and immune ring was also noted.

Corneal scrapings were taken in all patients from the base and margin of ulcer on slide with a drop of $10 \% \mathrm{KOH}$ and examined under microscope for the presence of yeast, filamentous septate and non septate hyphae. Relevant blood investigations were also done as and where required.

All patients were treated with topical and systemic antifungals, in addition to atropine eye ointment. Timolol 0.5\% eye drops were prescribed where intra ocular pressure (IOP) was raised. The first follow up was done at 2 weeks, followed by monthly, 3-monthly and 6-monthly checkups. The regression or progression of the ulcer, any change in treatment and the visual acuity were documented at each follow up.

RESULTS: In the present study, the maximum (40.18\%) number of patients was in the age group of 41-60 years. Most of the patients (61.42\%) were males who belonged to rural background $(n=116$; 91.34\%) and majority of them were illiterate (85.04\%) coming from lower socio economic status $(\mathrm{n}=114 ; 89.76 \%)$ (Table No 1). Occupation wise, the most frequently affected patients were farmers (39.37\%), followed by labourers (31.50\%) (Table no. 2). The highest number ( $n=44 ; 34.65 \%)$ of patients presented to us between October to December, followed by July to September ( $\mathrm{n}=35$; 27.56\%) (Table No. 3).

Analyzing the predisposing factors for fungal keratitis, a past history of trauma, positive in $48.03 \%$ patients, was the commonest. Use of topical steroids was documented in $25.20 \%$ cases and that of traditional eye medicines (TEM) in $11.81 \%$. History of diabetes was present in $7.87 \%$ patients while co-existing ocular diseases were seen in $26.76 \%$ (Table No. 4 ).

The ulcer was central in most of the cases (78.74\%) and measured $>4 \mathrm{~mm}$ in diameter in $46.46 \%$ patients. It was associated with hypopyon in $29.13 \%$, while satellite lesions and immune ring were seen in $15.75 \%$ and $7.87 \%$ patients respectively. 
Visual acuity was recorded in 125; two patients were less than one year of age, so their visual acuity could not be recorded. In this study, $58.40 \%$ of patients had vision up to $1 / 60$ at the time of presentation and $21.60 \%$ of patients had visual acuity $>6 / 60$. At final follow up, $48 \%$ had visual acuity up to1/60, $21.6 \%$ had between $1 / 60-6 / 60$, and $30.4 \%$ had $>6 / 60$.

$\mathrm{KOH}$ mount of scrapings from the ulcer showed that $63.7 \%$ patients were affected by filamentous fungi while $6.3 \%$ had infection by yeast.

Corneal opacity was the most common complication in this study, seen in $90.55 \%$ patients. Vascularisation was seen in $27.56 \%$ while corneal perforation occurred in $8.66 \%$ cases. Other complications observed were descemetocoele (7.09\%) and anterior staphyloma (1.57\%) (Table No. 5).

The factors which could affect the final visual outcome in these patients were assessed and these included age of the patients, day of presentation, history of topical steroid instillation, use of TEM, location of the ulcer, associated hypopyon and type of fungi isolated from ulcer. It was found that patients aged more than 40 years $(\mathrm{p}<0.05)$ and those presenting after 7 days $(\mathrm{p}<0.05)$, with history of topical steroid $(\mathrm{p}<0.05)$ use had a significantly poorer visual outcome. Similarly patients with central ulcers $(\mathrm{p}<0.05)$, especially those associated with hypopyon $(\mathrm{p}<0.05 \%)$ also had a significantly less favourable visual outcome. However, use of TEM and type of fungal infection were not significantly related to poor outcome in terms of visual acuity (Table No. 7).

DISCUSSION: The present study was an observational study done on 127 consecutive patients of fungal keratitis diagnosed on the basis of clinical characteristics and confirmed by KOH mount.

The maximum number of cases $(66.16 \%)$ belonged to the age group of 21 to 60 years and majority (61.42\%) of the patients were males. Out of the 127 patients enrolled in this study, $89.78 \%$ patients came from low socio economic status and only $8.66 \%$ were from the urban background, suggesting that fungal keratitis is a disease more prevalent in poor people and those living in villages. Occupation wise, maximum numbers of patients in our study were farmers $(39.37 \%)$ and labourers $(31.50 \%)$. Studying the seasonal variation, maximum numbers of patients of fungal keratitis reported during October to December (34.65\%) followed by July- September (27.56\%).

$M$ Jayahar Bharathi et al[7] found that the maximum numbers of patients $(66.85 \%)$ were between the ages 21 to 50 years. Lixin Xie et al[8]found that patients between 41 to 50 years of age were most (31.0\%) frequently affected, followed by those between 31 to 40 years $(26.5 \%)$ and 51 to 60 years $(21.1 \%)$.

Regarding gender distribution, a male preponderance was also reported by $\mathrm{M}$ Jayahar Bharathi et al,[7] Reema Nath et al,,[9]Prajna Lalitha et al ${ }^{[10]}$ in their studies $(65.02 \%, 67.6 \%$ and $55.6 \%$ respectively).

Occupation wise, $\mathrm{M}$ Jayahar Bharathi et al[7] found that $64.75 \%$ of patients were farmers $(\mathrm{P}<0.0001)$. Lixin Xie et al ${ }^{[8]}$ reported that $89.9 \%$ of patients of fungal corneal ulcers were farm workers, $4.1 \%$ were physical labourers, and $2.8 \%$ were non-manual employees.

Lixin Xie et al[8] also found that the peak in incidence of fungal keratitis occurred in the months of October to December, followed by July to September.

In our study, ninety five patients had predisposing factors for fungal keratitis. Out of them, $48.03 \%$ of patients had trauma before onset of symptoms, topical steroid drop instillation (25.2\%), use of traditional eyes medicines (11.81\%), chronic dacrocystitis $(11.81 \%)$, lid and lid margins abnormalities (6.30\%), blepharitis (5.51\%), Bell's palsy (1.57\%), dry eye $(1.57 \%)$ and history of diabetes (7.87\%) were other predisposing factors. 


\section{ORIGINAL ARTICLE}

M Jayahar Bharathiet al[7] found that corneal trauma (92.15\%) was the predominant predisposing factor and the correlation between trauma and fungal keratitis was highly significant $(\mathrm{p}<0.0001) .61 .28 \%$ patients had corneal injury with vegetative matter and this correlation was highly significant $(\mathrm{p}<0.0001)$. Co-existing ocular diseases were seen in $6.67 \%$ of patients. Use of corticosteroids predisposing to fungal keratitis accounted for $13(1.19 \%)$ cases, $16.07 \%$ patients had an associated systemic disease.

Bastola P et al[11] reported that trauma or injury to cornea (56.71\%), prior topical steroids use $(11.71 \%)$ and chronic ocular surface disorders (10.00\%) were the most common predisposing risk factors, followed by systemic diseases.

Reema Nath et al[9] noted that diabetes was a significant systemic predisposing factor in mixed bacterial and fungal infections in $11.1 \%$ cases, blocked naso-lacrimal duct was the local predisposing factor in $11.1 \%$ of cases. Ocular trauma was found to be associated with $76.4 \%$ cases.

In our study, $78.74 \%$ of patients had ulcer with central location, $46.46 \%$ had more than $4 \mathrm{~mm}$ of diameter, $29.13 \%$ had hypopyon, $15.75 \%$ had satellite lesions, and $7.87 \%$ and $3.15 \%$ had immune ring and pigmentation respectively.

Ashok Kumar Narsani et al[12] found that $68.1 \%$ eyes had larger ulcers (diameter $>5 \mathrm{~mm}$ ), typical satellite lesions were seen in $16.38 \%$ patients, hypopyon was present in $60.3 \%$ patients and 2.59\% patients had corneal perforation. Lixin Xie et al ${ }^{[8]}$ reported that $51.5 \%$ patients had larger ulcers (diameter $>6 \mathrm{~mm}$ ), $46.3 \%$ had hypopyon, $6.7 \%$ had elevated intraocular pressure, and $0.9 \%$ had complicated cataract.

In our study on mycotic keratitis, factors affecting visual outcome i.e. final visual acuity up to $6 / 60$ were age $>40$ years (77.38\%), presentation after 7 days of onset of symptoms $(82.22 \%)$, use of topical steroid (90.63\%), use of topical TEM (80\%), central ulcer $(87.76 \%)$, presence of hypopyon $(89.19 \%)$ and septate fungi infection $(74.36 \%)$. However, TEM use $(p=0.526)$ and septate fungi infection $(\mathrm{p}=0.241)$ were not statistically significant as compared to others.

Lalitha $\mathrm{P}$ et al[10] found that predictors of treatment failure in fungal keratitis were ulcers that exceeded $14 \mathrm{~mm}^{2}(\mathrm{p}=0.009)$, presence of hypopyon $(\mathrm{p}=0.003)$ and those infected with Aspergillus $(\mathrm{p}=0.003)$.

Regina L Sun et al[13] studied cases ofCandidakeratitis. Visual outcome was 20/60 or better in all $6(100 \%)$ medically treated eyes with good presenting visual acuity but in only 5 (24\%) with worse initial vision $(\mathrm{p}=0.002)$.

Prajna NV et al[14] found that predictors for worse 3-month visual acuity include older age $(\mathrm{p}=0.024)$, worse presentation visual acuity $(\mathrm{p}<0.001)$, larger infiltrate size at presentation $(\mathrm{p}<0.001)$, and pigmented ulcer $(\mathrm{p}=0.030)$. Larger infiltrate size at presentation was a significant predictor of worse 3 -month infiltrate/scar size $(\mathrm{p}<0.001)$. Larger epithelial defect size was a significant predictor of perforation $(\mathrm{p}=0.0013)$. Predictors of longer time to re-epithelialization include infiltrate size at presentation $(\mathrm{p}<0.001)$ and older age $(\mathrm{p}=0.025)$.

CONCLUSION: Fungal keratitis continues to be a significant cause of ocular morbidity in rural illiterate population following agricultural trauma. Application of topical steroid drops, TEM use and other predisposing factors lead to the exacerbation of infection, thus affecting final visual acuity.

An increase has been seen in number and severity of presentation of fungal keratitis cases.

This can be attributed to the fact that most of the people here are from rural area and are engaged in agricultural activity. Besides this, they do not present to the hospital early as symptoms 


\section{ORIGINAL ARTICLE}

are less compared to signs. Coupled with this is ignorance and lack of education in patients, which prompts them for use of self-medications and also to take treatment from local practitioners which often results in injudicious use of topical steroid eye drops. Thus, adequate protection during outdoor activities, patient education and awareness, minimization of topical steroids/Traditional eye medicines use and early institution of appropriate antifungal therapy are practical means to reduce the burden of visual impairment due to fungal keratitis.

\section{BIBLIOGRAPHY:}

1. Leck AK, P A Thomas, J Kaliamurthy, E Ackuaku, M John, M J Newman et al. Aetiology of suppurative corneal ulcers in Ghana and South India, and epidemiology of fungal keratitis. Br J. Ophthalmol 2002; 86:1211-5.

2. Chowdhary A, Singh K. Spectrum of fungal keratitis in North India. Cornea2005; 24:8-15.

3. Srinivasan M, Gonzales CA, George C. Epidemiology and aetiological diagnosis of corneal ulceration in Madurai, South India. Br J Ophthalmol 1997; 81:965-71.

4. Sharma S, Srinivasan M, George C.J. The Current status of fusarium species in mycotic keratitis in South India. Indian J Med. Microbiol 1993; 11:140-7.

5. Upadhyay M. P, Karmacharya PC, Koirala S, Tuladhar NR, Bryan LE, Smolin G, Whitcher JP. Epidemological characteristics, predisposing factors, and etilogical diagnosis of corneal ulceration in Nepal. Am. J. Opthalmol 1991; 111: 92-9.

6. Prajna VN, Pillai MR, Manimegalai TK, Srinivasan M. Use of traditional eye medicines by corneal ulcer patients presenting to a hospital in South India. Indian J Ophthalmol 1999; 47:15-8.

7. M Jayahar Bharathi, R Ramakrishnan, S Vasu, R Meenakshi, R Palaniappan. Epidemiological characteristics and laboratory diagnosis of fungal keratitis. A three-year study. Indian J Ophthalmol 2003; 51: 315-21.

8. Lixin Xie, Wenxian Zhong, Weiyun Shi, Shiying Sun. Spectrum of Fungal Keratitis in North China. Ophthalmology 2006; 113: 1943-48.

9. Reema Nath, Syamanta Baruah, Lahari Saikia, Bhanu Devi, A K Borthakur, J Mahanta. Mycotic corneal ulcers in upper Assam. Indian J Ophthalmol 2011; 59: 367-71.

10. Prajna Lalitha, Namperumalsamy Venkatesh Prajna, Amit Kabra, Kannan Mahadevan, Muthaiah Srinivasan. Risk Factors for Treatment Outcome in Fungal Keratitis. Ophthalmology 2006; 113: 526-30.

11. Bastola P, Mishra A, Chaudhary N, Nath HK, Mehrotra AN. Spectrum of Mycotic corneal ulcers in Mid-Western peripheral region of Terrain belt of Nepal and Indo-Nepal Border. NJMS 2013; 2: 42-7.

12. Ashok Kumar Narsani, Partab Rai Nangdev, Sajjad Ali Surhio, Mahesh Kumar, Shafi Muhammad Jatoi. Demographic Pattern, Risk Factors, Clinical and Microbiological Characteristics of Fungal Keratitis. JLUMHS 2012; 11: 01.

13. Regina L. Sun, Dan B. Jones, Kirk R. Wilhelmus. Clinical Characteristics and Outcome of Candida Keratitis. Am J Ophthalmol. 2007; 143: 1043-5.

14. N Venkatesh Prajna, T Krishnan, J Mascarenhas, M Srinivasan CE Oldenburg, CM Toutain-Kidd et al. Predictors of outcome in fungal keratitis. Eye 2012; 26:1226-31. 


\section{ORIGINAL ARTICLE}

\begin{tabular}{|c|c|c|c|}
\hline \multirow{2}{*}{$\begin{array}{c}\text { SL. } \\
\text { NO. }\end{array}$} & \multirow{2}{*}{ AREA } & \multicolumn{2}{|c|}{ PATIENTS } \\
\cline { 3 - 4 } & & NUMBER & PERCENTAGE \\
\hline 1. & Urban & 11 & $08.66 \%$ \\
\hline 2. & Rural & 116 & $91.34 \%$ \\
\hline \multicolumn{2}{|c|}{ TOTAL } & $\mathbf{1 2 7}$ & $\mathbf{1 0 0 \%}$ \\
\multicolumn{3}{|c|}{ TABLE 1: URBAN/RURAL } \\
\hline
\end{tabular}

\begin{tabular}{|c|c|c|c|}
\hline \multirow{2}{*}{$\begin{array}{c}\text { SL. } \\
\text { NO. }\end{array}$} & \multirow{2}{*}{ OCCUPATION } & \multicolumn{2}{|c|}{ PATIENTS } \\
\cline { 3 - 4 } & & NUMBER & PERCENTAGE \\
\hline 1. & Farmers & 50 & $39.37 \%$ \\
\hline 2. & Laborers & 40 & $31.50 \%$ \\
\hline 3. & Housewives & 19 & $14.96 \%$ \\
\hline 4. & Drivers & 2 & $01.57 \%$ \\
\hline 5. & Others & 16 & $12.60 \%$ \\
\hline \multicolumn{2}{|c|}{ TOTAL } & $\mathbf{1 2 7}$ & $\mathbf{1 0 0 . 0 0 \%}$ \\
\hline
\end{tabular}

\section{TABLE 2: OCCUPATION WISE DISTRIBUTION}

\begin{tabular}{|c|c|c|c|}
\hline \multirow{2}{*}{$\begin{array}{c}\text { SL. } \\
\text { NO. }\end{array}$} & \multirow{2}{*}{ MONTH } & \multicolumn{2}{|c|}{ PATIENTS } \\
\cline { 3 - 4 } & & NUMBER & PERCENTAGE \\
\hline 1. & January - March & 25 & $19.69 \%$ \\
\hline 2. & April - June & 23 & $18.10 \%$ \\
\hline 3. & July-September & 35 & $27.56 \%$ \\
\hline 4. & October - December & 44 & $34.65 \%$ \\
\hline \multicolumn{2}{|c|}{ TOTAL } & $\mathbf{1 2 7}$ & $\mathbf{1 0 0 . 0 0 \%}$ \\
\hline
\end{tabular}

TABLE 3: SEASONAL VARIATION

\begin{tabular}{|c|c|c|c|}
\hline \multirow{2}{*}{$\begin{array}{c}\text { SL. } \\
\text { NO. }\end{array}$} & PREDISPOSING & \multicolumn{2}{c|}{ PATIENTS } \\
\cline { 3 - 4 } & FACTORS & NUMBER & PERCENTAGE \\
\hline 1. & History of trauma & 61 & $48.03 \%$ \\
\hline 2. & Topical steroid drop instillation & 32 & $25.20 \%$ \\
\hline 3. & Use of Traditional eye medicines & 15 & $11.81 \%$ \\
\hline 4. & Chronic dacrocystitis & 15 & $11.81 \%$ \\
\hline 5. & Lid \& lid margins abnormalities & 08 & $06.30 \%$ \\
\hline 6. & Blepharitis & 07 & $05.51 \%$ \\
\hline 7. & Bell's palsy & 02 & $01.57 \%$ \\
\hline 8. & Dry eye & 10 & $01.57 \%$ \\
\hline 9. & History of Diabetes & $07.87 \%$ \\
\hline \multicolumn{2}{|c|}{ TABLE 4: PREDISPOSING FACTORS FOR FUNGAL KERATITIS } \\
\hline
\end{tabular}




\section{ORIGINAL ARTICLE}

\begin{tabular}{|c|c|c|c|}
\hline \multirow{2}{*}{$\begin{array}{c}\text { SL. } \\
\text { NO. }\end{array}$} & \multirow{2}{*}{ COMPLICATIONS } & \multicolumn{2}{|c|}{ PATIENTS } \\
\cline { 3 - 4 } & & NUMBER & PERCENTAGE \\
\hline 1. & Corneal opacity & 115 & $90.55 \%$ \\
\hline 2 & Vascularisation & 35 & $27.56 \%$ \\
\hline 3. & Perforation & 11 & $08.66 \%$ \\
\hline 4. & Descemetocele & 9 & $07.09 \%$ \\
\hline 5. & Anterior staphyloma & 2 & $01.57 \%$ \\
\hline
\end{tabular}

TABLE 5: COMPLICATIONS OF FUNGAL KERATITIS

\begin{tabular}{|c|c|c|c|c|c|c|c|c|c|c|c|}
\hline \multirow{3}{*}{$\begin{array}{l}\text { SL. } \\
\text { NO. }\end{array}$} & \multirow{3}{*}{$\begin{array}{l}\text { VISUAL } \\
\text { ACUITY }\end{array}$} & \multicolumn{10}{|c|}{ PATIENTS } \\
\hline & & \multicolumn{2}{|c|}{$\begin{array}{c}\text { AT } \\
\text { PESENTATION }\end{array}$} & \multicolumn{2}{|c|}{$\begin{array}{c}\text { AT 1 }{ }^{\text {st }} \\
\text { FOLLOW UP }\end{array}$} & \multicolumn{2}{|c|}{$\begin{array}{c}\text { AT } 2^{\text {nd }} \\
\text { FOLLOW UP }\end{array}$} & \multicolumn{2}{|c|}{$\begin{array}{c}\text { AT } 3^{\text {rd }} \\
\text { FOLLOW UP }\end{array}$} & \multicolumn{2}{|c|}{$\begin{array}{c}\text { FINAL } \\
\text { FOLLOW UP }\end{array}$} \\
\hline & & NO & $\%$ & NO & $\%$ & NO & $\%$ & NO & $\%$ & NO & $\%$ \\
\hline 1. & Up to $1 / 60$ & 73 & 58.40 & 63 & 50.40 & 61 & 48.80 & 60 & 48.00 & 60 & 48.00 \\
\hline 2. & $>1 / 60-6 / 60$ & 25 & 20.00 & 26 & 20.80 & 27 & 21.60 & 27 & 21.60 & 27 & 21.60 \\
\hline 3. & $>6 / 60-6 / 18$ & 20 & 16.00 & 18 & 14.40 & 18 & 14.40 & 18 & 14.40 & 18 & 14.40 \\
\hline 4. & $>6 / 18$ & 07 & 05.60 & 18 & 14.40 & 19 & 15.20 & 20 & 16.00 & 20 & 16.00 \\
\hline & TOTAL & 125 & 100 & 125 & 100 & 125 & 100 & 125 & 100 & 125 & 100 \\
\hline
\end{tabular}

\begin{tabular}{|c|c|c|c|c|c|c|c|c|}
\hline \multirow{3}{*}{$\begin{array}{l}\text { SL. } \\
\text { NO. }\end{array}$} & \multirow{2}{*}{\multicolumn{3}{|c|}{ FACTORS }} & \multicolumn{5}{|c|}{ FINAL VISUAL ACUITY } \\
\hline & & & & \multicolumn{2}{|c|}{ Up to $6 / 60$} & \multicolumn{2}{|c|}{$>6 / 60$} & \multirow{2}{*}{$P$ value } \\
\hline & & & NO & NO & $\%$ & NO & $\%$ & \\
\hline \multirow{2}{*}{1.} & \multirow{2}{*}{ Age } & Up to $40 y r s$ & 41 & 22 & 53.66 & 19 & 46.34 & \multirow{2}{*}{$\mathrm{P}<0.05$} \\
\hline & & $>40 y r s$ & 84 & 65 & 77.38 & 19 & 22.62 & \\
\hline \multirow{2}{*}{2.} & \multirow{2}{*}{ Day of presentation } & Up to 7 days & 35 & 13 & 37.14 & 22 & 62.86 & \multirow{2}{*}{$\mathrm{P}<0.05$} \\
\hline & & $>7$ days & 90 & 74 & 82.22 & 16 & 17.78 & \\
\hline \multirow{2}{*}{3.} & \multirow{2}{*}{ Steroid drops instillation } & Yes & 32 & 29 & 90.63 & 3 & 9.37 & \multirow{2}{*}{$\mathrm{P}<0.05$} \\
\hline & & No & 93 & 58 & 62.37 & 35 & 37.63 & \\
\hline \multirow{2}{*}{4.} & \multirow{2}{*}{ TEM use } & Yes & 15 & 12 & 80 & 3 & 20 & \multirow{2}{*}{$\mathrm{P}=0.526$} \\
\hline & & No & 110 & 75 & 68.18 & 35 & 31.82 & \\
\hline \multirow{2}{*}{5.} & \multirow{2}{*}{ Ulcer location } & Central & 98 & 86 & 87.76 & 12 & 12.24 & \multirow{2}{*}{$\mathrm{P}<0.05$} \\
\hline & & Peripheral & 27 & 1 & 3.70 & 26 & 96.30 & \\
\hline \multirow{2}{*}{6.} & \multirow{2}{*}{ Hypopyon } & Yes & 37 & 33 & 89.19 & 4 & 10.81 & \multirow{2}{*}{$\mathrm{P}<0.05$} \\
\hline & & No & 88 & 54 & 61.36 & 34 & 38.64 & \\
\hline \multirow{3}{*}{7.} & \multirow{3}{*}{$\mathrm{KOH}$ picture } & Septate & 78 & 58 & 74.36 & 20 & 25.64 & \multirow{3}{*}{$\mathrm{P}=0.241$} \\
\hline & & Aseptate & 39 & 25 & 64.10 & 14 & 35.90 & \\
\hline & & Yeast & 8 & 4 & 50 & 4 & 50 & \\
\hline
\end{tabular}




\section{ORIGINAL ARTICLE}

\section{AUTHORS:}

1. Pankaj Choudhary

2. Sujatha Lakhtakia

3. Charudatt Chalisgoankar

4. Anamika Dwivedi

5. Kanchanbala Rathore

\section{PARTICULARS OF CONTRIBUTORS:}

1. Associate Professor, Department of Ophthalmology, Shyam Shah Medical College, Rewa, Madhya Pradesh.

2. Assistant Professor, Department of Ophthalmology, Shyam Shah Medical College, Rewa, Madhya Pradesh.

3. Assistant Professor, Department of Ophthalmology, Shyam Shah Medical College, Rewa, Madhya Pradesh.

FINANCIAL OR OTHER COMPETING INTERESTS: None
4. Assistant Professor, Department of Ophthalmology, Shyam Shah Medical College, Rewa, Madhya Pradesh.

5. Resident, Department of Ophthalmology, Shyam Shah Medical College, Rewa, Madhya Pradesh.

\section{NAME ADDRESS EMAIL ID OF THE CORRESPONDING AUTHOR:}

Dr. Pankaj Choudhary,

E-1, Doctor's Colony, Rewa, Madhya Pradesh.

E-mail: pankaj17choudhary@gmail.com

Date of Submission: 23/05/2015. Date of Peer Review: 24/05/2015. Date of Acceptance: 09/07/2015. Date of Publishing: 15/07/2015. 